\title{
VZA ve Tobit Model ile Kamu Ağız ve Diş Sağlığı Merkezleri Performanslarının İncelenmesi ${ }^{1}$
}

\author{
Oğuzhan YÜKSEL ${ }^{2}$
}

\begin{abstract}
Özet: A $\breve{g} 1 z$ ve diş sağlı̆̆ı, genel sağlık ve yaşam kalitesinin göstergelerindendir. Ağız ve diş hastalıkları küresel halk sağlığı problemlerinden olup, en sık görülen bulaşıcı olmayan hastalıklardandır. Bu araştırmanın amacı, Sağlık Bakanlığı'na bağlı Ağız ve Diş Sağlığı Merkezleri (ADSM)'nin 2014-2018 dönemindeki etkinlik düzeylerini saptamaktır. Araştırmada yöntem olarak, ADSM'lerin teknik verimliliğini ölçmek için Veri Zarflama Analizi (VZA) CCR yöntemi kullanılmıştır. Ayrıca etkinliğe etki eden faktörlerin tespit edilebilmesi için Tobit analizi yapılmıştır. Araştırmanın evrenini Türkiye'de, 2014-2018 yılları arasında faaliyetini aralıksız sürdürmüş, ünit sayısı 50 ve üzerinde olan Sağlık Bakanlığı'na bağlı ADSM'ler oluşturmaktadır. Araştırmada örneklem seçilmemiş, evrenin tamamına ulaşılmıştır. Girdi olarak ünit sayısı ve toplam diş hekimi sayısı; çıktı olarak ise muayene sayısı, diş çekimi sayısı, konservatif tedavi sayısı, endodontik tedavi sayısı değişkenleri kullanılmıştır. 2014-2018 VZA verimlilik skorları yıllara göre sırasıyla ortalama 0,750, 0,782, 0,759,0,733, 0,716 olarak tespit edilmiştir. VZA'da elde edilen etkinlik skorları bağımlı değişken olarak alınarak Tobit analizi yapılmış ve sonuçlar yorumlanmıştır. 2018 yılına ait VZA sonuçlarında; girdi değişkenlerinden ünit sayısının \%21,81 ve toplam diş hekimi sayısının \%24,17 oranında azaltılması önerilmektedir. Çıktı değişkenlerinden endodontik tedavi sayısının \%34,59, muayene edilen hasta sayısının \%3,45 ve konservatif tedavi sayısının \%2,77 oranında artırılması gerektiği görülmektedir.
\end{abstract}

Anahtar Kelimeler: Ağız ve Diş Sağlığı, Etkinlik, Tobit Analizi, Veri Zarflama Analizi.

\section{Investigation of the Performance of Public Oral and Dental Health Centers in Turkey with DEA and Tobit Model}

\begin{abstract}
Oral and dental health is one of the indicators of general health and quality of life. Oral and dental diseases are global public health problems and are one of the most common non-communicable diseases. The purpose of this research is to determine the efficiency levels of Oral and Dental Health Centers (ODHC) affiliated to the Ministry of Health in the period 2014-2018. As a method in the study, Data Envelopment Analysis (DEA) CCR method was used to measure the technical efficiency of ODHCs. In addition, Tobit analysis was performed to determine the factors affecting the efficiency. In Turkey, the universe of research has continued to operate continuously between 2014-2018, the number of units is 50 and more ODHCs affiliated to the Ministry of Health. The sample was not selected in the study, and the whole universe was reached. Number of units and total number of dentists as inputs; as output, number of patients examined, number of tooth extractions, number of conservative treatments, number of endodontic treatments were used. The 2014-2018 DEA efficiency scores were determined as an average of 0.750, 0.782, 0.759, $0.733,0.716$, respectively, by years. Efficiency scores obtained in DEA were taken as dependent variables and Tobit analysis was performed and the results were interpreted. In the 2018 DEA results, it is proposed to reduce the number of units from input variables by $21.81 \%$ and the total number of dentists by $24.17 \%$. Among the output variables, it is seen that the number of endodontic treatments should be increased by $34.59 \%$, the number of examined patients by $3.45 \%$ and the number of conservative treatments by $2.77 \%$.
\end{abstract}

Keywords: Oral and Dental Health, Efficiency, Tobit Analysis, Data Envelopment Analysis.

\footnotetext{
${ }^{1} \mathrm{Bu}$ çalışma "Sağlık Bakanlığı Ağı ve Diş Sağlığı Merkezlerinin Verimlilik Analizi” isimli doktora tezinden türetilmiştir.

${ }^{2}$ Orcid ID: https://orcid.org/0000-0003-0539-4136, Sağlık Bakanlığı, Isparta Ağız ve Diş Sağlığ1 Merkezi, Diş Hekimi, Isparta-Türkiye, oguzhan@doctor.com
} 


\section{Summary}

To raise community awareness increased in all treatment costs for oral and dental health and reduce dental caries by reducing the incidence of various health policies are being developed to prevent the deterioration of oral health. Oral and dental health services in Turkey are carried out by state/city hospitals, educational and research hospitals, some hospitals associated with municipalities and family health centers. Oral and dental health centers (ODHC), which are spread by the Ministry of Health, aim to reduce oral diseases and secondary diseases caused by them. With all these developments, the share of the state sector in the access, provision and use of dental services to the public in Turkey has been increasing in recent years. Currently, at least one ODHC operates in each province within the framework of population-based planning throughout the country. These centers, which have been opened, have become organizations that spend a small part of the important resources that are scarce in the health system over time. With lower inputs, doing the necessary work to achieve higher outputs will lead to the correct use of resources.

The aim of this study is to determine the activity levels of ODHCs under the Ministry of Health in the period 2014-2018. In 2018, 159 ODHC operates in all of Turkey. Among them, ODHC's, which have worked actively for 5 consecutive years since 2014, served in the same region with the same name, reached a capacity of 50 units and more in 2017, were included in the sample group. The universe of research consists of 46 ODHC affiliated to the Ministry of Health, which provides oral and dental health services in Turkey, which has the above conditions. In the study, the sample was not selected and the entire universe was reached. As a method of research, the Data Envelopment Analysis (DEA) CCR method was used to measure the technical efficiency of ODHC. In addition, Tobit analysis was performed to determine the factors affecting the efficiency.

Number of units and total number of dentists as inputs; as output, number of patients examined, number of tooth extractions, number of conservative treatments, number of endodontic treatments were used. The 20142018 DEA efficiency scores were determined as an average of $0.750,0.782,0.759,0.733,0.716$, respectively, by years. Among decision-making units (DMU), the lowest efficiency values are M38 with a score of 0.232 in 2014 and M15 with a score of 0.405 in 2015. In 2016, 2017 and 2018, M27 had scores of $0.383,0.337,0.289$, respectively. It stands out as the only DMU M18 that is efficient over the entire 5-year time period. Although the M5 efficiency was good in 2014-2017, it remained below the full score in 2018 with 0.887. Similarly, the M10 is inefficient only in 2014, the M30 is inefficient only in 2015, and the M46 is inefficient only in 2016, while they are efficient in the other 4 years. In the 2014-2018 period, it stands out as the only DMU M38 whose activity score is constantly increasing compared to the previous year. According to the results of the analysis, there is no DMU with efficiency below $20 \%$.

Efficiency scores obtained in DEA were taken as dependent variables and Tobit analysis was performed and the results were interpreted. By examining the Tobit analysis results with DEA CCR scores, it was understood that the number of endodontic treatments alone from output variables in 2014 was statistically positive at a 5\% significance level and had an effect on efficiency by about $0.16 \%$. In the 2018 DEA results, it is proposed to reduce the number of units from input variables by $21.81 \%$ and the total number of dentists by $24.17 \%$. Among the output variables, it is seen that the number of endodontic treatments should be increased by $34.59 \%$, the number of tooth extractions by $13.21 \%$, the number of examined patients by $3.45 \%$ and the number of conservative treatments by $2.77 \%$.

The lowest average DEA CCR score was achieved in 2018 (0.716). The lowest DEA CCR score was 0.232 in 2014. Compared to the regions, the lowest DEA CCR score was found in Central Anatolia (0.661) and the highest in Southeastern Anatolia (0.852). The highest average DEA CCR score was 22 ODHC in the range of 50-74 units. In this case, a small number of units can be said to increase efficiency. In addition to other studies examining ODHC, the findings obtained by using DEA and Tobit analysis together are intended to contribute to the literature. In the study, the aefficiency scores obtained for ODHCs are not absolute results, but relative efficiency results. Therefore, a DMU or variable that will be added and/or subtracted from the model used may lead to changes in the results of the analysis. With this in mind, ODHC managers should measure efficiency levels by selecting input and output variables that best reflect productivity levels. ODHC's performance levels should be monitored during certain periods, and the results should be shared with management and ODHC managers. ODHC managers should develop efficiency awareness about resource use and improve human resource management processes by analyzing the workload of centers.

Keywords: Oral and Dental Health, Efficiency, Tobit Analysis, Data Envelopment Analysis 


\section{Giriş}

Toplumların en büyük zenginliği sağlıklarıdır. Sağlık sorunlarını önemli ölçüde çözmüş olan ülkelerde genel olarak ekonomik, siyasal ve sosyal konularda önemli ilerlemeler görüldüğünü söyleyebiliriz (Ağırbaş vd., 2011: 734). Bundan dolayı sağlık sektörü herkes için yüksek bir öncelik haline gelmektedir. Sağlık hizmetlerinin yönetilmesi, sağlık harcamaları üzerinde önemli bir etkiye sahiptir (Alaiad vd., 2018: 23). Dünya Sağlık Örgütü (DSÖ)'ne göre sağlık; “yalnızca hastalık veya sakatlık durumunun olmayışı değil bedensel, ruhsal ve sosyal yönden tam bir iyilik hali” olarak tanımlanmıştır (WHO, 1948: 1-3).

Ağız ve diş sağlığı ise DSÖ tarafından "bireyin 1sırma, gülme, konuşma, çiğneme ve psikososyal açıdan sağlıklı olma halini sınırlandıracak şiddette ağız ve yüz ağrısı, ağız ve çevre doku kanseri, ağız enfeksiyonu ve yaraları, dişeti hastalıkları, diş çürümesi, diş kaybı gibi rahatsılılkların görülmemesi” olarak tanımlamaktadır (Mohanta, 2017: 12). Sağlık kavramı bütün olarak düşünüldüğünde; eğitim durumu, yaşam tarzı, beslenme alışkanlıkları ve sosyo-ekonomik faktörler gibi çeşitli değişkenlerin sağlık üzerinde etkileri bulunduğu anlaşılmaktadır.

Ağız ve diş sağlığıyla genel sağlı durumu ve çeşitli sistemik hastalıklar arasında, çoğu zaman doğru orantılı bir ilişki olduğu konusunda fazla sayıda bilimsel kanıtlar vardır. Bireylerin yaşam kalitelerinin yükselmesi, ağız ve diş sağlığı açısından optimal şartların sağlanması ve bunun sürekliliğinin olması ağız hijyeninin iyi seviyelerde olmasına bağlıdır. Ağız hijyeni iyi bireylerden oluşan bir topluma ulaşmanın temelinde; koruyucu diş hekimliğine önem verilmesi, ağız sağlı̆̆1 ve önemi hakkında temel bilgilerin erken yaşlarda öğretilmesi, düzenli diş hekimi kontrollerinin yapılması ve gerekli tedbirlerin alınarak uygulanması bulunmaktadır.

Bir sağlık sisteminin en önemli amaçları; sağlık hizmetlerine ayrılan kaynakları verimli kullanmak, sağlık hizmetleri sunumunu iyi organize etmek, sağlık hizmetlerine erişimi kolaylaştırmak, kişileri finansal risklere karşı korumak ve tüm bunların sonucunda toplumun sağlık seviyesini yükseltmektir (Uğurluoğlu ve Çelik, 2005: 7). Tüm dünyada olduğu gibi Türkiye'de de ağız ve diş sağlığına yönelik artan tedavi maliyetlerini düşürerek toplumu bilinçlendirmek, diş çürük insidansını azaltarak oral sağlığın bozulmasını engellemek için çeşitli sağlık politikaları geliştirilmektedir. Türkiye'de ağız ve diş sağlığı hizmetleri devlet/şehir hastaneleri, eğitim ve araştırma hastaneleri, belediyelere bağlı bazı hastaneler ve aile sağlığı merkezlerince yürütülmektedir. Sağlık Bakanlığı tarafından yaygınlaştırılan ağız ve diş sağlığı merkezleri (ADSM) ve ağız ve diş sağlığı hastaneleri (ADSH) ile oral hastalıklar ve bunların neden olduğu sekonder rahatsızlıkların azaltılması hedeflenmektedir. Tüm bu gelişmelerle birlikte, Türkiye'de son yıllarda diş hekimliği hizmetlerinin halka erişiminde, sunulması ve kullanılmasında devlet sektörünün payı artmaktadır. Günümüzde, ülke genelinde nüfusa göre yapılan planlamalar dâhilinde 
her ilde en az bir ADSM/ADSH faaliyet göstermektedir. Açılan bu merkezler, ilerleyen zamanla birlikte sağlık sistemi içerisindeki kıt olan önemli kaynakların, azımsanmayacak bir kısmını harcayan kuruluşlar haline gelmişlerdir. Daha düşük girdilerle, daha yüksek çıktılar elde edilmesi için gerekli çalışmaların yapılması kaynakların doğru kullanımına öncülük edecektir.

Literatür incelendiğinde verimlilik ve etkinlik hem sağlık sektöründe hem de diğer sektörlerde önem ve öncelik verilen (Yiğit, 2020:24) ve oldukça yüksek düzeyde akademik çalışma yapılan konular arasında yer almaktadır. Sağlık kurumlarında verimsizliğin en önemli sebebi mevcut girdilerle (çalışanlar, malzeme, teknoloji, cihazlar, bina vb.) üretilen çıktıların (muayene sayıları, ameliyat sayıları, gelir vb.) yetersiz olmasından ileri gelmektedir (Şahin, 2008: 11, Wang vd., 1999: 85). Sağlık hizmetlerinde oldukça yüksek düzeyde olan israfı önlemek için performans ve verimlilik analizlerin yapılması hayati önem taşımaktadır. Bu nedenle sağlık kuruluşlarının verimlilik seviyeleri belirlenmeli, verimli olmayanlar ise saptanarak girdi ve çıktılardaki değişim miktarları tespit edilmelidir.

Türkiye'de ağız ve diş sağlığı harcamaları, 2013 yılı toplam sağlık harcamalarının \%5,3’ünü oluşturmaktadır (Atasever ve Örnek, 2018: 13). Türkiye'de 2018 verilerine göre 34.045 diş hekimi (TDB, 2019: 2) ve 159 ADSM/ADSH bulunmaktadır. Bu sebeplerle ağız ve diş sağlığı alanında kaynakların etkin ve verimli harcanması, genel sağlık sisteminin verimliliğini de yakından ilgilendirmektedir. Bu araştırmanın amacı, Türkiye'de ADSM'lerin 2014-2018 arasındaki zaman diliminde verimlilik düzeylerini ve değişimlerini Veri Zarflama Analizi (VZA) ve Tobit analizi yardımıyla belirlemektir. ADSM'leri inceleyen diğer çalışmalara ek olarak, VZA ve Tobit analizinin birlikte kullanılmasıyla ulaşılan bulguların literatüre katkı sağlaması amaçlanmıştır.

\section{YÖNTEM}

Bu araştırmada; Türkiye'de faaliyet gösteren Sağlık Bakanlı̆̆g'na bağlı ADSM'lerin etkinliklerini tespit etmek amacıyla Veri Zarflama Analizi (VZA), ayrıca etkinliğe etki eden faktörlerin incelenebilmesi için Tobit analiz metodlarından yararlanılmıștır.

2018 yılında Türkiye genelinde 159 tane ADSM/ADSH mevcuttur. Bunların arasından; 2014 yılından itibaren ardışık 5 yıllık süreçte aktif olarak çalışmış, aynı isimle aynı bölgede hizmet veren, 2017 yılında 50 ünit ve üzerinde kapasiteye ulaşmış ADSM'ler örneklem grubuna alınmıştır. Araştırmanın evrenini; yukarıda sayılan şartlara haiz Türkiye'de ağız ve diş sağlı̆̆ı hizmeti sunan Sağlık Bakanlığı'na bağlı 46 tane ADSM oluşturmaktadır. Araştırmada örneklem seçilmemiş olup tüm evrene ulaşılmıştır. Tablo 1'de çalışmaya dâhil edilen merkezler ve kodları yer almaktadır. 
Tablo 1. Araştırmada İncelenen KVB'ler ve Kodları

\begin{tabular}{clcl}
\hline Kurum Kodu & \multicolumn{1}{c}{ Kurum Adı } & Kurum Kodu & \multicolumn{1}{c}{ Kurum Adı } \\
\hline M1 & Adana Fatma Kemal Timuçin ADSH & M24 & İstanbul Okmeydanı ADSH \\
\hline M2 & Adıyaman ADSM & M25 & İstanbul Sancaktepe ADSM \\
\hline M3 & Ankara 75.Y1 ADSH & M26 & İzmir Alsancak ADSM \\
\hline M4 & Ankara Balgat ADSM & M27 & İzmir Bornova ADSM \\
\hline M6 & Ankara Keçiören Osmanlı ADSM & M28 & İzmir Eğitim Diş Hastanesi \\
\hline M7 & Ankara Mamak ADSM & M29 & İzmir Karş1yaka ADSM \\
\hline M8 & Antalya ADSM & M30 & Kahramanmaraş ADSH \\
\hline M9 & Balıkesir ADSM & M31 & Kayseri Nimet Bayraktar ADSH \\
\hline M10 & Batman ADSM & M32 & Kocaeli Darıca ADSM \\
\hline M11 & Bursa ADSH & M33 & Konya ADSH \\
\hline M12 & Çankırı ADSM & M34 & Konya Beyhekim ADSM \\
\hline M13 & Denizli ADSH & M35 & Kütahya ADSM \\
\hline M14 & Diyarbakır ADSM & M36 & Malatya ADSH \\
\hline M15 & Elazığ ADSM & M37 & Manisa ADSM \\
\hline M16 & Erzurum ADSM & M38 & Mersin ADSH \\
\hline M17 & Eskişehir ADSH & M39 & Sakarya ADSH \\
\hline M18 & Gaziantep Şahinbey ADSM & M40 & Samsun ADSH \\
\hline M19 & Gaziantep Şehitkamil ADSM & M41 & Sivas ADSH \\
\hline M20 & İstanbul Ataşehir ADSH & M42 & Tekirdağ ADSH \\
\hline M21 & İstanbul Göztepe ADSM & M43 & Tekirdă̆ Çorlu ADSM \\
\hline M22 & İstanbul Güngören ADSM & M44 & Tokat ADSM \\
\hline M23 & İstanbul Kartal ADSM & M45 & Trabzon ADSH \\
\hline & & M46 & Van ADSM
\end{tabular}

\subsection{Veri Zarflama Analizi}

Farrell'in (1957: 253-281) yaptığ1, 1957 tarihli "The Measurement of Productive Efficiency" çalışmadan ilham alınarak 1978 yılında Charnes, Cooper ve Rhodes (isimlerinin baş harfleri ile CCR modeli olarak adlandırılan) tarafından hazırlanan araştırmayla VZA ilk kez kullanılmıştır. CCR modeli ile bir Karar Verme Birimi (KVB) için tek girdi-çıktı oranı kullanmak yerine, çoklu girdi-çıktı oranları her bir KVB için kullanılabilir hale gelmiştir (Charnes vd., 1996: 6). Charnes ve arkadaşları ölçeğe göre sabit getiriyi (Constant Retuns to Scale:CRS) ele alarak analize derinlik katmışlardır (Temür, 2010: 10, Ramanathan, 2005: 44).

VZA ile birbirine benzer girdilerle çıktılar üretmek isteyen, aynı amaç ve hedeflere sahip KVB'ler karşılaştırılabilmekte ve göreceli etkinlik kıyaslamaları yapılabilmektedir (Bhat vd., 1985: 310, Bayraktutan vd., 2010: 13). VZA sonuçları hastanelerin kaynak ihtiyaçları konusunda anlamlı sonuçlar ortaya koymasa da kaynak kullanımı ve kaynak tahsisi arasındaki ilişkiye ait önemli bilgiler sunmaktadır (Al-Shammari, 1999: 889). Sağlık alanında genellikle girdilerin denetlenebilmesinin daha kolay olmasına karşın çıktıların planlanması ve kontrolünün zor olması nedeniyle girdi yönelimli VZA tekniği kabul görmektedir (Şahin, 2008: 28). Sağlık kurumlarında çıktılar için sunulan potansiyel iyileştirmeler bazı durumlarda yerine getirilebilir sınırları 
aşabilmekte ve akabinde etik sorunları beraberinde getirebilmektedir. Bu sebeplerle çalışmada girdi odaklı VZA CCR modeli kullanılmıştır.

Analiz edilecek $n$ adet karar biriminde $m$ adet girdi kullanarak, $s$ adet çıktı üretildiğini ve $k$ karar birimi için toplam faktör verimliliğinin hesaplandığını düşünelim. $x_{i j}>0$ parametresi, $j . \mathrm{KVB}$ tarafından kullanılan $i$. girdi miktarını; $y_{r j}>0$ parametresi ise üretilen $r$. çıktı miktarını göstermektedir. Bu karar problemi için değişkenler, $k$. KVB'nin $i$. girdi ve $r$. çıktıları için vereceği ağırlıklardır ki bunlar sırasıyla $v_{i k}$ ve $u_{r k}$ olarak gösterilmektedir. Kesirli doğrusal programlama modelinin amaç fonksiyonu, $k$. KVB için toplam ağırlıklandırılmış çıktıların, girdilere oranının maksimizasyonudur (Cingi ve Tarım, 2000: 6). Girdi yönelimli CCR yöntemi, CRS yaklaşımını temel alarak toplam etkinliği değerlendirmektedir (Tarım, 2001: 61). Amaç fonksiyonu şu şekilde yazılabilir (Tütek vd., 2012: 232-233; Charnes vd., 1978: 430):

$$
\operatorname{maxh}_{k}=\frac{\sum_{r=1}^{s} u_{r k} y_{r k}}{\sum_{i=1}^{m} v_{i k} x_{i k}}
$$

Yukarıdaki formülle hesaplanan toplam girdi ve çıtı değerleri sanal değerler olup, bu sayede tüm girdi ve çıktılar tek bir değer yardımıyla gösterilebilmektedir. Burada dikkat edilmesi gereken husus girdi ve çıktılara verilecek faktör ağırlıklarının nasıl belirleneceğidir. $\mathrm{Bu}$ faktörler yardımıyla etkinlik skorları 0-1 arasında olmaktadır (Özata, 2004: 95-97).

\subsubsection{Kullanılan Değişkenler ve Açıklamaları}

Literatürdeki daha önce yapılmış çalışmalar 1şı̆̆ında; girdi olarak ünit sayısı (US) ve toplam diş hekimi sayısı (DTS), çıktı olarak ise muayene sayısı (MS), diş çekimi sayısı (DCS), konservatif tedavi sayısı (KTS) ve endodontik tedavi sayısı (ETS) belirlenmiştir. Tablo 2'de çalışmada VZA için kullanılan değişkenler ve açıklamaları bulunmaktadır.

Tablo 2. Kullanılan Değişkenler ve Açıklamaları

\begin{tabular}{ll}
\hline \multicolumn{1}{c}{ Değişken Adı } & \multicolumn{1}{c}{ Açıklaması } \\
\hline $\begin{array}{l}\text { Ünit Sayısı (US) } \\
\begin{array}{l}\text { Toplam Diş Hekimi Sayısı } \\
\text { (DTS) }\end{array}\end{array}$ & Diş hekimlerinin muayene veya tedaviler esnasında kullandıkları hasta koltuğu sayısı \\
\hline Muayene Sayısı (MS) & Muayene edilen hasta sayısı sayısı ile diş hekimi sayısının toplamı \\
\hline $\begin{array}{l}\text { Diş Çekimi Sayısı (DCS) } \\
\text { Konservatif Tedavi Sayısı } \\
\text { (KTS) }\end{array}$ & $\begin{array}{l}\text { Diş çekimimi sayılarının toplamı veya başka sebeplerle kaybedilen diş sert doku kayıplarının onarılması (dolgu) } \\
\text { sayısı }\end{array}$ \\
\hline $\begin{array}{l}\text { Endodontik Tedavi Sayısı } \\
\text { (ETS) }\end{array}$ & Kanal (kök) tedavisi sayısı \\
\hline
\end{tabular}




\subsection{Tobit Analizi}

Sınırlı bağımlı değişkene sahip modelleri açıklamakta yaygın olarak kullanılan Tobit modeli, bağımlı değişkenin pozitif olmayan gözlemlerinin sıfır ile değiştirildiği doğrusal bir regresyon modelidir (Deaton ve Irish, 1984: 59). Sansürlenmiş normal regresyon modeli olarak da adlandırılan Tobit regresyon modeli, ilk kez 1958 yılında James Tobin tarafından geliştirilmiştir (Greene, 2008: 871).

Tobit regresyonu genellikle; bağımlı değişkenin belli bir aralıkta olduğu sınırlı bağımlı değişkeni olan durumlarda kullanılmaktadır. Belirli bir aralık haricindeki gözlemler tamamen kaybedilmişse model kesikli (truncated); örneklem kümesinden en azından dışsal ya da bağımsız değişkenler gözlemlenebiliyorsa model sansürlü (cencored) olarak adlandırılmaktadır (Amemiya, 1984: 3). Kesikli modellerde; belli bir oranda sınırlanmış bağımlı ve bağımsız değişkenler mevcuttur ya da bazı verilerin sistematik olarak araştırma kapsamından çıkarılması gerekmektedir (Salamov, 2017: 66).

\subsubsection{Tobit Tahmin Değişkenleri}

Merkezlerin etkinlik skorları VZA ile belirlendikten sonra; muayene sayısı, diş çekimi sayısı, konservatif tedavi sayısı ve endodontik tedavi sayısı değişkenlerinin toplam etkinlik üzerindeki etkisi Tobit Model ile incelenmiştir. Tobit analizinde kullanılmak üzere tahmin değişkenleri Tablo 3'de gösterilmektedir.

Tablo 3. Tobit Model Tahmin Değişkenleri

\begin{tabular}{l|cc}
\hline \multicolumn{2}{c}{ Bağımlı Değişken } & \multicolumn{2}{c}{ Bă̆ımsız Değişken } \\
\hline \multirow{4}{*}{ İlgili Yılın Etkinlik Skoru $(Y)$} & $X_{1}$ & Muayene Sayısı \\
\cline { 2 - 3 } & $X_{2}$ & Diş Çekimi Sayısı \\
\cline { 2 - 3 } & $X_{3}$ & Konservatif Tedavi Sayısı \\
\cline { 2 - 3 } & $\mathrm{X}_{4}$ & Endodontik Tedavi Sayısı \\
\hline
\end{tabular}

Her yıl için bir regresyon denklemi oluşturulmuştur. Aşağıdaki denklem setinde $t=2014, \ldots, 2018^{\prime} e$ kadar olmak üzeri TECCRt değişkenleri CCR modeli kullanılarak elde edilen etkinlik skorunu göstermektedir. Aşağıda oluşturulan formül gösterilmektedir.

$$
T E_{C C R t}=\beta_{0}+\beta_{1} L O G(M S)_{t}+\beta_{2} L O G(D C S)_{t}+\beta_{3} L O G(K T S)_{t}+\beta_{4} L O G(E T S)_{t}
$$

Her formülde, KVB sayısı kadar veri bulunmaktadır. CCR yöntemi için 2014-2018 arasındaki 5 yıllık zaman diliminde her yıl için ayrı ayrı yapılan Tobit Analiz sonuçları bulgular bölümünde tablolar haline getirilerek yorumlanmıştır. 


\section{BULGULAR}

Araştırmada kullanılan VZA ve Tobit modeline ait bulgular detaylı bir biçimde farklı bölümler halinde ele alınmıştır.

\subsection{VZA Araștırma Bulguları}

ADSM'lerin teknik verimlilikleri, ölçeğe göre sabit getiri varsayımını kullanan girdi yönelimli VZA CCR yöntemiyle analiz edilmesiyle ölçülmüştür. Her KVB'nin girdi yönelimli CCR etkinlik skorları hesaplanmış, verimsiz merkezler (ilk 3 KVB) için potansiyel iyileştirme önerileri sunulmuştur.

KVB'lerin 2014-2018 yılları VZA sonuçlarına göre, CCR skorları sırasıyla ortalama 0,750, 0,782, 0,759, 0,733, 0,716 olarak tespit edilmiştir. KVB'ler içerisinde en düşük verimlilik değerlerine 2014 yılında 0,232 skoruyla M38, 2015 yılında 0,405 skoruyla M15, 2016, 2017 ve 2018 yıllarında sırasıyla 0,383, 0,337, 0,289 skorlarıyla M27 sahip olmuştur. 5 yıllık zaman diliminin tamamında verimli çıkan tek KVB M18 olarak göze çarpmaktadır. M5 2014-2017 y1lları arasında etkin olsa da 2018 yılında 0,887 ile etkinlik skorunun altında kalmıştır. Benzer şekilde M10 sadece 2014 yılında, M30 sadece 2015 y1lında, M46 sadece 2016 y1lında verimsizken diğer 4 yılda verimlidirler. 20142018 periyodunda bir önceki seneye göre etkinlik skoru sürekli artan tek KVB M38 olarak göze çarpmaktadır. Tablo 4'de VZA CCR sonuçları ayrıntılı olarak yer almaktadır.

Şekil 1'de 2014-2018 arasındaki 5 yıllık süreçte CCR sonuçlarına göre etkinlik skorlarının dağılımı görülmektedir. Analiz sonuçlarına göre \%20’nin altında verimliliğe sahip KVB yoktur. \%30’un altında ise 2014 yılında 1 ve 2015 yılında 1 KVB bulunmaktadır. En büyük yoğunlaşma olan bölge 2014 yılında 15 KVB ile \%60 ile \%69,99 arasındaki dilimde görülmüştür. 2018 yılında, \%60-69,99 ve \%80-89,99 dilimleri arasında 11'er KVB bulunmaktadır.

Şekil 1. CCR Skorlarının Dağılımı

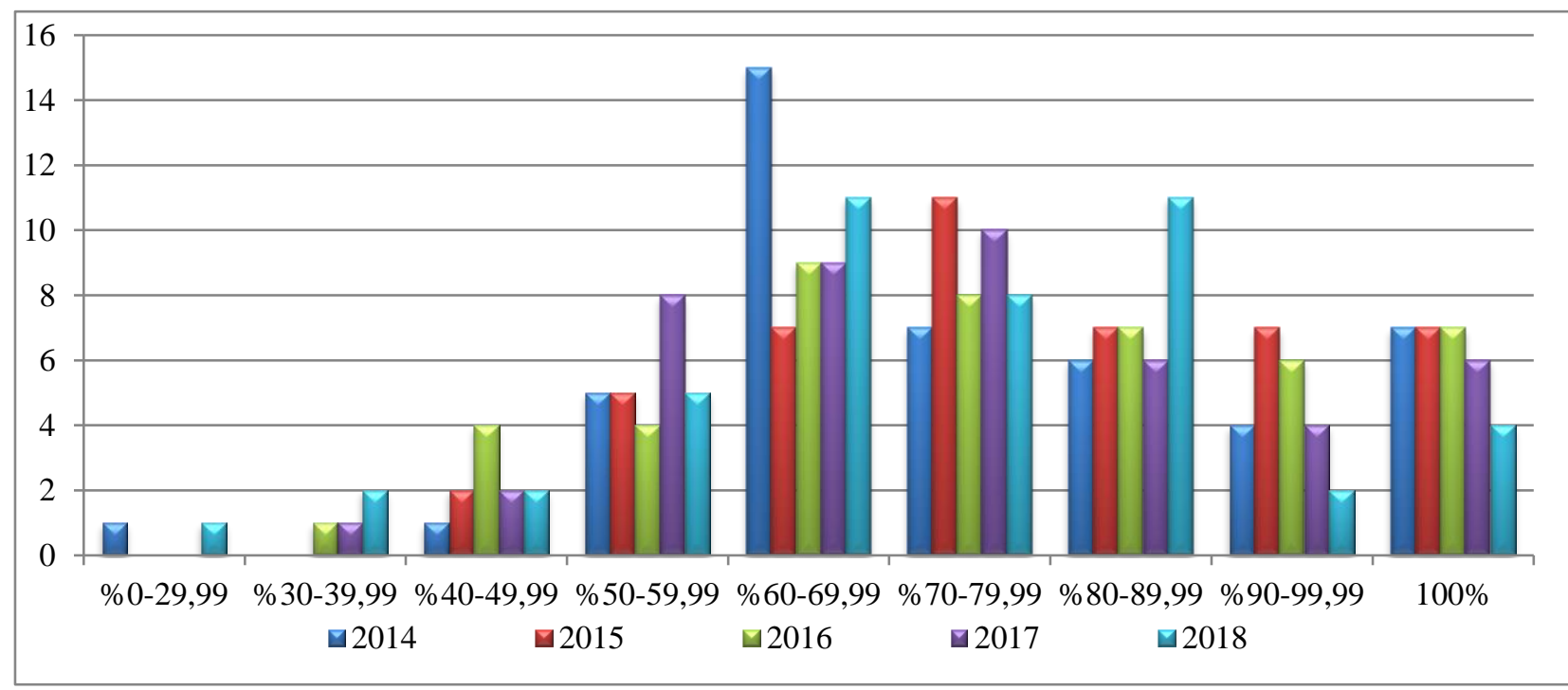


ASED | Aksaray Üniversitesi Sosyal Bilimler Enstitüsü Dergisi

Y11: 2020 (Aralık) / Cilt:4 / Say1:2 ISSN: 2619-9211

Tablo 4. 2014-2018 VZA Skorları (CCR)

KVB KODU

M1



M2

M4

M5

M6 0,776

M7 0,574

M8 0,502

M9 0,917

M10 $\quad 0,975$

M11

M12

M13

M14

M15

M16

M17

M18

M19

M20

M21

M22

M23

M24

M25

M26

M27

M28

M29

M30

M31

M32

M33

M34

M35

M36

M37

M38

M39

M40

M41

M42

M43

M44

M45

M46

Ortalama

Std. Sapma

Minimum
2014

0,657

0,715

0,895

0,616

0,802

0,484

0,542

0,769

0,680

1

0,569

0,691

0,654

0,701

0,677

0,835

0,846

0,513

0,792

0,625

0,969

0,663

0,606

0,785

0,607

0,661

0,232

0,684

0,864

0,665

0,635

0,965

$1 \quad 0,772$

1

1

0,177

0,232

0,790
2015

0,899

0,761

0,671

0,804

0,591

0,641

0,922

0,855

0,616

0,661

0,597

0,405

0,768

0,742

0,614

0,680

0,838

0,707

0,842

0,930

0,930

0,576

0,715

0,742

0,925

0,664

0,838

0,573

0,779

0,592

0,937

0,411

0,718

0,836

1

0,772

1

0,782

0,160

0,405

2016

0,446

0,968

0,496

1

0,463

0,548

1

1

0,671

0,534

0,830

0,621

0,731

1

0,700

0,725

0,663

0,810

0,685

0,820

0,967

0,383

0,711

0,662

0,958

0,873

0,595

0,515

0,616

0,790

0,886

0,478

0,800

0,993

0,788

0,692

0,927

0,622

0,757

0,940

0,759

0,181

0,383

0,383

KVB kodlaması esas alınarak ilk 3 sıradaki

iyileştirme önerileri sunulmuştur. Örneğin M1 kodlu KVB’nin 2014 yılı CCR sonuçlarına göre

etkinlik skoru 0,893'tür. Bu merkezin etkin seviyede yer alması için girdi değişkenlerinden ünit sayısını \%10,69 oranında, toplam diş hekimi sayısını ise \%15,58 oranında azaltması gerekmektedir. 
Ayrıca M1 kodlu merkezin diş çekimi sayını yaklaşık \%18 ve konservatif tedavi sayısını ise \%0,79 oranında arttırması gerekmektedir. 2014 yılında M1 için referans alınması gereken KVB'ler; yaklaşık \%99 oranında M36 ve \%1 oranında M45 olarak belirlenmiştir. M1 kodlu KVB'nin araştırmanın en güncel yılı olan 2018 sonuçlarına bakıldığında ise etkinlik skoru 0,514 olarak bulunmuştur. 2018 yılı verileri dikkate alındığında M1 kodlu merkezin girdilerinden ünit sayısını $\% 50,28$ oranında ve toplam diş hekimi sayısını ise $\% 48,61$ oranında azaltması gerektiği anlaşılmaktadır. Çıktı değişkenlerinden ise diş çekimi sayısını \%5,3 oranında ve endodontik tedavi sayısını \%13,33 oranında artırması gerekmektedir. Bunun için ünit sayısını 103'den 51'e, toplam diş hekimi sayısını ise $88^{\prime}$ 'den 45 'e düşürmeli, ayrıca diş çekimi sayısını 65.944'den 69.441'e ve endodontik tedavi sayısını 32.644'den 36.995'e çıkartmak için gerekli tedbirleri alması öngörülmüştür. Tablo 5'de görüleceği üzere; 2018 yılı için benzemeye çalışılması geren KVB'ler yaklaşık \%42 oranında M10 ve \%43 oranında M46 olarak bulunmuştur.

2018 yılının en güncel verileri yansıtması nedeniyle, bu yıla ait CCR yöntemi iyileştirme oranları detaylandırılmış ve Şekil 2'de gösterilmiştir. Girdi değişkenlerinden ünit sayısının \%21,81 oranında ve toplam diş hekimi sayısının $\% 24,17$ oranında azaltılması gerektiği görülmektedir. Çıktı değişkenlerinden endodontik tedavi sayısının \%34,59, diş çekimi sayısının \%13,21, muayene edilen hasta sayısının \%3,45 ve konservatif tedavi sayısının \%2,77 oranında artırılmasının etkinlik için gerekli olduğu sonucuna varılmıştır.

Şekil 2. 2018 Y1lı Potansiyel İyileştirme Oranları (CCR)

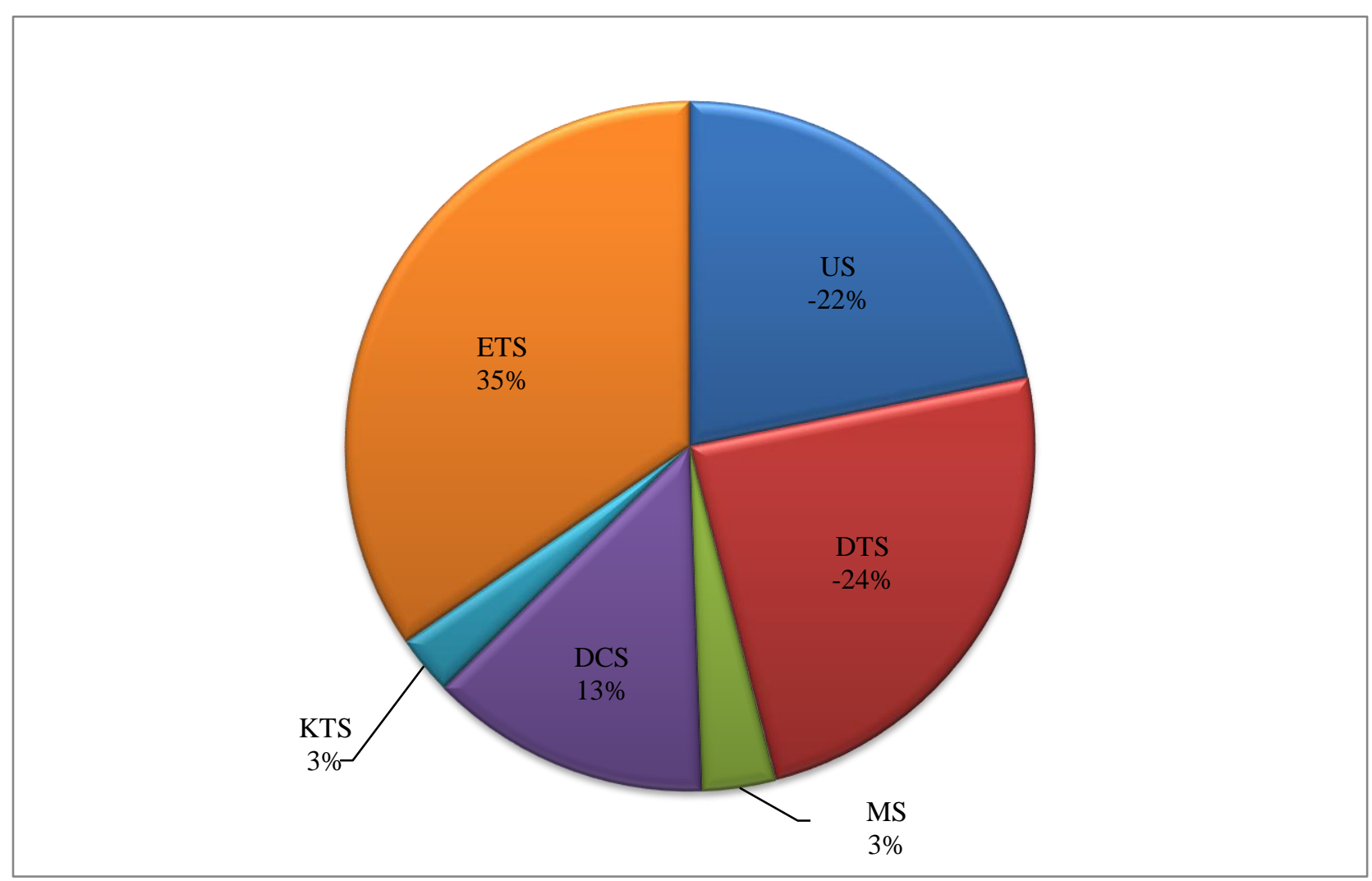


Tablo 5. CCR Skorlarına Göre Potansiyel İyileştirme ve Referans Tablosu (İlk 3 KVB)

\begin{tabular}{|c|c|c|c|c|c|c|c|c|c|c|c|c|c|c|c|c|c|}
\hline \multirow[b]{2}{*}{ KVB } & \multirow{2}{*}{\multicolumn{2}{|c|}{ Girdi ve Çıktı }} & \multicolumn{3}{|c|}{2014} & \multicolumn{3}{|c|}{2015} & \multicolumn{3}{|c|}{2016} & \multicolumn{3}{|c|}{2017} & \multicolumn{3}{|c|}{2018} \\
\hline & & & Mevcut & Hedef & İyileştirme & Mevcut & Hedef & İyileştirme & Mevcut & Hedef & İyileştirme & Mevcut & Hedef & İyileştirme & Mevcut & Hedef & İyileştirme \\
\hline \multirow{8}{*}{ M1 } & \multicolumn{2}{|c|}{ Etkinlik Skoru } & \multicolumn{3}{|c|}{0,893} & \multicolumn{3}{|c|}{1} & \multicolumn{3}{|c|}{0,446} & \multicolumn{3}{|c|}{0,437} & \multicolumn{3}{|c|}{0,514} \\
\hline & \multirow{2}{*}{ Girdi } & US & 54 & 48 & $-10,69 \%$ & 49 & 49 & $0,00 \%$ & 119 & 53 & $-55,40 \%$ & 141 & 62 & $-56,32 \%$ & 103 & 51 & $-50,28 \%$ \\
\hline & & DTS & 64 & 54 & $-15,58 \%$ & 85 & 85 & $0,00 \%$ & 121 & 52 & $-56,66 \%$ & 115 & 49 & $-57,63 \%$ & 88 & 45 & $-48,61 \%$ \\
\hline & \multirow{4}{*}{ Çıktı } & MS & 329297 & 329297 & $0,00 \%$ & 311614 & 311614 & $0,00 \%$ & 338027 & 338027 & $0,00 \%$ & 395051 & 395051 & $0,00 \%$ & 345211 & 345211 & $0,00 \%$ \\
\hline & & DCS & 64336 & 75911 & $17,99 \%$ & 56135 & 56135 & $0,00 \%$ & 68690 & 79435 & $15,64 \%$ & 78720 & 89360 & $13,52 \%$ & 65944 & 69441 & $5,30 \%$ \\
\hline & & KTS & 78220 & 78841 & $0,79 \%$ & 86282 & 86282 & $0,00 \%$ & 109817 & 111816 & $1,82 \%$ & 116403 & 126725 & $8,87 \%$ & 118877 & 118877 & $0,00 \%$ \\
\hline & & ETS & 20794 & 20794 & $0,00 \%$ & 24763 & 24763 & $0,00 \%$ & 29779 & 29779 & $0,00 \%$ & 31535 & 39539 & $25,38 \%$ & 32644 & 36995 & $13,33 \%$ \\
\hline & \multicolumn{2}{|c|}{ Referans KVB } & \multicolumn{3}{|c|}{ M36 0,996; M45 0,163 } & \multicolumn{3}{|c|}{ M1 1} & \multicolumn{3}{|c|}{ M11 0,272; M30 0,335 } & \multicolumn{3}{|c|}{ M46 0,919 } & \multicolumn{3}{|c|}{ M10 0,425; M46 0,427 } \\
\hline \multirow{8}{*}{ M2 } & \multicolumn{2}{|c|}{ Etkinlik Skoru } & \multicolumn{3}{|c|}{0,687} & \multicolumn{3}{|c|}{0,899} & \multicolumn{3}{|c|}{\begin{tabular}{r}
\multicolumn{1}{c}{0,968} \\
\end{tabular}} & & 0,956 & & & 0,899 & \\
\hline & Cindi & US & 52 & 36 & $-31,26 \%$ & 58 & 52 & $-10,06 \%$ & 58 & 56 & $-3,18 \%$ & 58 & 55 & $-4,44 \%$ & 60 & 49 & $-18,79 \%$ \\
\hline & Grral & DTS & 54 & 37 & $-31,26 \%$ & 57 & 51 & $-10,06 \%$ & 58 & 55 & $-5,66 \%$ & 53 & 51 & $-4,44 \%$ & 53 & 48 & $-10,13 \%$ \\
\hline & & MS & 234276 & 234276 & $0,00 \%$ & 237236 & 237236 & $0,00 \%$ & 280316 & 327353 & $16,78 \%$ & 262651 & 304227 & $15,83 \%$ & 276310 & 318374 & $15,22 \%$ \\
\hline & Cllt & DCS & 50420 & 62436 & $23,83 \%$ & 45904 & 46735 & $1,81 \%$ & 52145 & 73002 & $40,00 \%$ & 55201 & 55201 & $0,00 \%$ & 58056 & 58056 & $0,00 \%$ \\
\hline & ÇIKtI & KTS & 60204 & 64311 & $6,82 \%$ & 84589 & 84589 & $0,00 \%$ & 148050 & 148050 & $0,00 \%$ & 147203 & 147203 & $0,00 \%$ & 157332 & 157332 & $0,00 \%$ \\
\hline & & ETS & 15406 & 15406 & $0,00 \%$ & 20970 & 25655 & $22,34 \%$ & 47443 & 47443 & $0,00 \%$ & 40820 & 47018 & $15,18 \%$ & 37118 & 44882 & $20,92 \%$ \\
\hline & Refer: & KVB & M18 0,1 & M44 0,0 & M46 0,668 & M5 0,628 & M10 0,194 & M18 0,272 & M1 & ,319; M31 & 0,585 & M5 0,43 & M10 0,38 & M30 0,160 & M10 & 0,$882 ; \mathrm{M} 4$ & 0,016 \\
\hline & Etkinl & Skoru & & 0,657 & & & 0,761 & & & 0,731 & & & 0,608 & & & 0,602 & \\
\hline & Girdi & US & 156 & 98 & $-37,39 \%$ & 151 & 115 & $-23,95 \%$ & 151 & 110 & $-26,87 \%$ & 152 & 92 & $-39,22 \%$ & 152 & 87 & $-43,07 \%$ \\
\hline & जirtit & DTS & 148 & 97 & $-34,31 \%$ & 143 & 109 & $-23,95 \%$ & 156 & 96 & $-38,25 \%$ & 147 & 77 & $-47,62 \%$ & 134 & 81 & $-39,82 \%$ \\
\hline & & MS & 462665 & 462665 & $0,00 \%$ & 467317 & 509341 & $8,99 \%$ & 591164 & 624844 & $5,70 \%$ & 562978 & 562978 & $0,00 \%$ & 565957 & 574066 & $1,43 \%$ \\
\hline IVIJ & C,llt & DCS & 75908 & 97331 & $28,22 \%$ & 74755 & 81952 & $9,63 \%$ & 111322 & 111322 & $0,00 \%$ & 108475 & 110220 & $1,61 \%$ & 109989 & 109989 & $0,00 \%$ \\
\hline & दुरासu & KTS & 142725 & 142725 & $0,00 \%$ & 157908 & 157908 & $0,00 \%$ & 209272 & 261475 & $24,94 \%$ & 221028 & 221028 & $0,00 \%$ & 199799 & 241407 & $20,82 \%$ \\
\hline & & ETS & 56297 & 56297 & $0,00 \%$ & 59683 & 59683 & $0,00 \%$ & 98475 & 98475 & $0,00 \%$ & 79322 & 79322 & $0,00 \%$ & 71387 & 71387 & $0,00 \%$ \\
\hline & Refera & KVB & M5 0,12 & M30 1,0 & M44 0,956 & M5 0,276 & M10 0,615 & M45 1,584 & M1 & ,538; M31 & 0,431 & M10 0,6 & ; M30 0,2 & ; M46 0,580 & M1 & 1,156; M4 & 0,364 \\
\hline
\end{tabular}




\subsection{Etkinliğe Etki Eden Faktörlerin Tobit Analizi ile Araştırılması}

CCR modeli ile elde edilen teknik etkinlik skorlarının Sansürlenmiş (Kesikli) Normal Tobit Analiz Metodu kullanılarak (Method: ML-Censored Normal (TOBIT) (Quadratic Hill Climbing)) Tobit regresyonu ile tahminler yapılmıştır. VZA'dan sonra devam edilen bu adım, ADSM'lerin etkinliğinde hangi faktörlerin etkili olduğunu anlayabilmek açısından önemlidir. Bu tahminde; VZA'da kullanılan çıktılar bağımsız değişken, etkinlik skorları ise bağımlı değişken olarak alınmıştır.

VZA'da CCR ve BCC yöntemleriyle bulunan skorların Tobit analizi ile etkinliğe etki eden değişkenlerinin ortak etkinliği belirlenecek ve bu analiz yönteminin tahmindeki katkısı ortaya konulacaktır. Tahmin değerlerinin anlamlılık düzeyleri $\mathrm{p} \leq 0,01 / 0,01 \leq \mathrm{p} \leq 0,05 / 0,05 \leq \mathrm{p} \leq 0,10$ olarak verilmiştir. Değerlerin 0,10'a eşit ya da küçük olması durumunda etkinlik üzerinde belirleyici role sahip oldukları söylenebilir. Analizler ve sonuçları Tablo 6' da verilmiştir.

CCR skorlarıyla yapılan Tobit analiz sonuçları incelendiğinde, 2014 yılında çıktı değişkenlerinden yalnız endodontik tedavi sayısının istatistiki olarak \%5 anlamlılık düzeyinde pozitif anlamlı olduğu ve etkinliğe yaklaşık \%0,16 oranında etkisi olduğu anlaşılmıştır. 2015, 2016, 2017 ve 2018 yıllarına bakıldığında çıktı değişkenlerinden hiçbirisinin etkinlik skoru üzerindeki etkisinin istatistiki olarak anlamlı olmadığı görülmüştür.

Tablo 6. Tobit Analiz Sonuçları

\begin{tabular}{|c|c|c|c|c|c|c|c|c|c|c|c|c|}
\hline & \multicolumn{4}{|c|}{2014} & \multicolumn{4}{|c|}{2015} & \multicolumn{4}{|c|}{2016} \\
\hline Değişken & 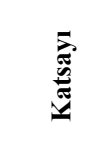 & 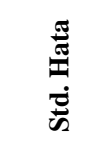 & 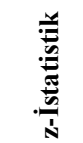 & $\dot{0}$ & 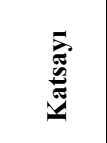 & 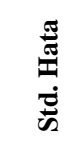 & 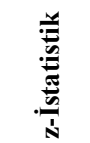 & $\dot{0}$ & & 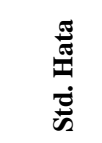 & 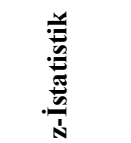 & $\dot{\stackrel{0}{0}}$ \\
\hline Sabit & $-0,767$ & 0,712 & $\begin{array}{c}- \\
1,077\end{array}$ & 0,282 & $-0,408$ & 0,812 & $\begin{array}{c}- \\
0,502\end{array}$ & 0,616 & $-0,781$ & 0,979 & $-0,798$ & 0,425 \\
\hline Diş Çekimi Sayısı & $-0,008$ & 0,119 & $0, \overline{-}$ & 0,946 & 0,005 & 0,12 & 0,044 & 0,965 & 0,184 & 0,143 & 1,288 & 0,198 \\
\hline $\begin{array}{c}\text { Endodontik Ted. } \\
\text { Sayısı }\end{array}$ & $0,158^{* * *}$ & 0,064 & 2,469 & 0,014 & 0,084 & 0,068 & 1,227 & 0,22 & 0,027 & 0,067 & 0,397 & 0,692 \\
\hline $\begin{array}{c}\text { Konservatif Ted. } \\
\text { Sayısı }\end{array}$ & $-0,15$ & 0,095 & $\begin{array}{c}- \\
1,577\end{array}$ & 0,115 & $-0,004$ & 0,092 & $\begin{array}{c}- \\
0,046\end{array}$ & 0,963 & $-0,012$ & 0,097 & $-0,119$ & 0,905 \\
\hline \multirow[t]{2}{*}{ Muayene Sayısı } & 0,14 & 0,172 & 0,817 & 0,414 & 0,029 & 0,17 & 0,17 & 0,865 & $-0,05$ & 0,205 & $-0,244$ & 0,807 \\
\hline & \multicolumn{4}{|c|}{ Hata Dağılımı } & \multicolumn{4}{|c|}{ Hata Dağılımı } & \multicolumn{4}{|c|}{ Hata Dağılımı } \\
\hline SCALE:C(6) & 0,156 & 0,016 & 9,592 & 0 & 0,151 & 0,016 & 9,592 & 0 & 0,167 & 0,017 & 9,592 & 0 \\
\hline Bağımlı Değ. Ort. & 0,75 & \multicolumn{2}{|c|}{$\begin{array}{l}\text { Bağımlı Değ. } \\
\text { Std. Hata }\end{array}$} & 0,177 & 0,782 & \multicolumn{2}{|c|}{$\begin{array}{l}\text { Bağımlı Değ. } \\
\text { Std. Hata }\end{array}$} & 0,16 & 0,759 & \multicolumn{2}{|c|}{$\begin{array}{c}\text { Bağımlı Değ. Std. } \\
\text { Hata }\end{array}$} & 0,181 \\
\hline $\begin{array}{c}\text { Regresyonun Std. } \\
\text { Hatası }\end{array}$ & 0,167 & \multicolumn{2}{|c|}{$\begin{array}{l}\text { Akaike Bilgi } \\
\text { Kriteri }\end{array}$} & $\begin{array}{c}- \\
0,623\end{array}$ & 0,162 & \multicolumn{2}{|c|}{$\begin{array}{l}\text { Akaike Bilgi } \\
\text { Kriteri }\end{array}$} & $\begin{array}{c}- \\
0,676\end{array}$ & 0,179 & \multicolumn{2}{|c|}{ Akaike Bilgi Kriteri } & $-0,483$ \\
\hline Kalıntı Kareleri & 1,113 & \multicolumn{2}{|c|}{ Schwarz Kriteri } & $\begin{array}{c}- \\
0,384 \\
\end{array}$ & 1,055 & \multicolumn{2}{|c|}{$\begin{array}{c}\text { Schwarz } \\
\text { Kriteri }\end{array}$} & $\begin{array}{c}- \\
0,438 \\
\end{array}$ & 1,28 & \multicolumn{2}{|c|}{ Schwarz Kriteri } & $-0,245$ \\
\hline Log Olabilirlik & 20,329 & \multirow{2}{*}{\multicolumn{2}{|c|}{$\begin{array}{c}\text { Hannan-Quinn } \\
\text { Kriteri }\end{array}$}} & \multirow{2}{*}{$\begin{array}{c}- \\
0,534\end{array}$} & 21,558 & \multirow{2}{*}{\multicolumn{2}{|c|}{$\begin{array}{c}\text { Hannan- } \\
\text { Quinn Kriteri }\end{array}$}} & \multirow{2}{*}{$\begin{array}{c}- \\
0,587\end{array}$} & 17,117 & \multirow{2}{*}{\multicolumn{2}{|c|}{ Hannan-Quinn Kriteri }} & \multirow{2}{*}{$-0,394$} \\
\hline $\begin{array}{l}\text { Ort. Log } \\
\text { Olabilirlik }\end{array}$ & 0,442 & & & & 0,469 & & & & 0,372 & & & \\
\hline
\end{tabular}




\section{Tablo 6'nın Devamı}

\begin{tabular}{|c|c|c|c|c|c|c|c|c|}
\hline & \multicolumn{4}{|c|}{2017} & \multicolumn{4}{|c|}{2018} \\
\hline Değişken & 嶌 & 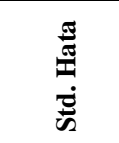 & 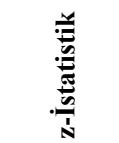 & $\dot{0}$ & 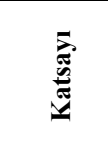 & 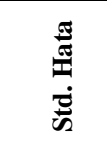 & 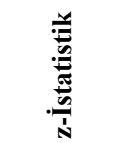 & $\dot{\stackrel{0}{0}}$ \\
\hline Sabit & $-0,669$ & 0,945 & $-0,708$ & 0,479 & $-1,215$ & 0,915 & $-1,327$ & 0,184 \\
\hline Diş Çekimi Sayısı & 0,157 & 0,126 & 1,239 & 0,215 & 0,189 & 0,116 & 1,627 & 0,104 \\
\hline Endodontik Ted. Sayısı & 0,027 & 0,067 & 0,402 & 0,688 & 0 & 0,068 & $-0,002$ & 0,998 \\
\hline Konservatif Ted. Sayısı & 0,003 & 0,088 & 0,029 & 0,977 & 0,084 & 0,072 & 1,156 & 0,248 \\
\hline \multirow[t]{2}{*}{ Muayene Sayısı } & $-0,05$ & 0,173 & $-0,288$ & 0,773 & $-0,089$ & 0,153 & $-0,581$ & 0,561 \\
\hline & \multicolumn{4}{|c|}{ Hata Dağılımı } & \multicolumn{4}{|c|}{ Hata Dağılımı } \\
\hline SCALE:C(6) & 0,167 & 0,017 & 9,592 & 0 & 0,154 & 0,016 & 9,592 & 0 \\
\hline Bağımlı Değ. Ort. & 0,733 & \multicolumn{2}{|c|}{$\begin{array}{c}\text { Bağımlı Değ. Std. } \\
\text { Hata }\end{array}$} & 0,179 & 0,716 & \multicolumn{2}{|c|}{ Bağımlı Değ. Std. Hata } & 0,175 \\
\hline Regresyonun Std. Hatası & 0,179 & \multicolumn{2}{|c|}{ Akaike Bilgi Kriteri } & $-0,479$ & 0,166 & \multicolumn{2}{|c|}{ Akaike Bilgi Kriteri } & $-0,638$ \\
\hline Kalıntı Kareleri & 1,285 & \multicolumn{2}{|c|}{ Schwarz Kriteri } & $-0,24$ & 1,096 & \multicolumn{2}{|c|}{ Schwarz Kriteri } & $-0,4$ \\
\hline Log Olabilirlik & 17,014 & \multirow{2}{*}{\multicolumn{2}{|c|}{$\begin{array}{l}\text { Hannan-Quinn } \\
\text { Kriteri }\end{array}$}} & \multirow{2}{*}{$-0,39$} & 20,683 & \multirow{2}{*}{\multicolumn{2}{|c|}{ Hannan-Quinn Kriteri }} & $-0,549$ \\
\hline Ort. Log Olabilirlik & 0,37 & & & & 0,45 & & & \\
\hline
\end{tabular}

\section{TARTIŞMA VE SONUÇ}

Sağlık hizmeti sunumunun yapı taşlarından biri olan ağız ve diş sağlığı merkezlerinin etkili ve verimli bir sağlık hizmet verebilmesi, düzenli olarak performanslarının değerlendirilmesine bağlıdır. Sürekli artış eğiliminde olan harcamalar düşünüldüğünde, toplam sağlık harcamalarının yaklaşık \%5-6'sını kullanan ağız ve diş sağlığı hizmeti sunan sağlık tesislerinin; kaynaklarını en uygun şekilde kullanmaları, strateji ve hedefleri doğrultusunda en iyi hizmeti üretmeleri gerekmektedir. VZA sonuçlarının özet hali Tablo 7'de verilmiştir. En düşük ortalama VZA skoru 2018 yılında $(0,716)$ elde edilmiştir. En düşük verimlilik puanı ise 2014 yılında 0,232’dir.

Tablo 7. VZA Özet Tablosu

\begin{tabular}{|cccccc|}
\hline & $\mathbf{2 0 1 4}$ & $\mathbf{2 0 1 5}$ & $\mathbf{2 0 1 6}$ & $\mathbf{2 0 1 7}$ & $\mathbf{2 0 1 8}$ \\
\hline $\begin{array}{c}\text { Ortalama Verimlilik } \\
\text { Skoru }\end{array}$ & 0,750 & 0,782 & 0,759 & 0,733 & 0,716 \\
\hline $\begin{array}{c}\text { En Düşük Verimlilik } \\
\text { Skoru }\end{array}$ & 0,232 & 0,405 & 0,383 & 0,337 & 0,289 \\
\hline Verimsiz KVB \% & 84,78 & 84,78 & 84,78 & 86,95 & 91,30 \\
\hline $\begin{array}{c}\text { Verimsiz KVB Ortalama } \\
\text { Skoru }\end{array}$ & 0,706 & 0,743 & 0,715 & 0,692 & 0,689 \\
\hline
\end{tabular}

ADSM'ler bölgelere, ünit sayılarına, diş hekimi sayılarına ve yıllık muayene sayılarına göre gruplandırılarak 2018 yılında karşılaştırılmıştır. Tablo 8'de KVB sayıları, ortalama CCR skorları, minimum, maksimum değerler ve standart sapmalar gösterilmiştir. Bölgelere göre kıyaslandığında en düşük verimlilik skoru İç Anadolu (0,661), en yüksek Güneydoğu Anadolu $(0,852)$ bölgesi olarak bulunmuştur. KVB'lerin geneline bakıldığında \%8,7'sinin Akdeniz Bölgesi'nde, \%15,2'sinin Ege Bölgesi'nde, \%8,7'sinin Doğu Anadolu Bölgesi'nde, \%10,8'inin Güneydoğu Anadolu Bölgesi'nde, \%24'ünün İç Anadolu Bölgesi'nde, \%6,5'inin Karadeniz Bölgesi'nde ve \%26’sının Marmara Bölgesi'nde yer aldığı tespit edilmiştir. 
Tablo 8. Çeşitli Değişkenlere Göre 2018 Yı1ı VZA Skorları

\begin{tabular}{|c|c|c|c|c|c|c|}
\hline Değişken & & KVB Sayısı & Ort. Skor & Min. & Mak. & Std.Sapma \\
\hline \multirow{8}{*}{ 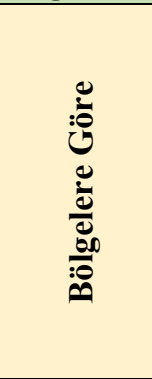 } & Akdeniz & 4 & 0,682 & 0,490 & 1,000 & 0,237 \\
\hline & Doğu Anadolu & 4 & 0,673 & 0,344 & 1,000 & 0,270 \\
\hline & Ege & 7 & 0,637 & 0,289 & 0,845 & 0,199 \\
\hline & Güneydoğu Anadolu & 5 & 0,852 & 0,670 & 1,000 & 0,162 \\
\hline & İç Anadolu & 11 & 0,661 & 0,391 & 0,887 & 0,161 \\
\hline & Karadeniz & 3 & 0,772 & 0,683 & 0,826 & 0,078 \\
\hline & Marmara & 12 & 0,768 & 0,574 & 0,982 & 0,119 \\
\hline & Genel Toplam & 46 & 0,716 & 0,289 & 1,000 & 0,175 \\
\hline \multirow{7}{*}{ 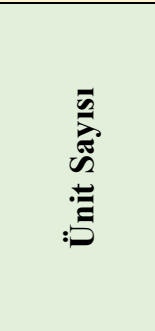 } & $50-74$ & 22 & 0,809 & 0,544 & 1,000 & 0,134 \\
\hline & $75-99$ & 8 & 0,652 & 0,501 & 0,808 & 0,088 \\
\hline & $100-124$ & 12 & 0,651 & 0,344 & 0,906 & 0,189 \\
\hline & $125-149$ & 1 & 0,289 & 0,289 & 0,289 & 0,000 \\
\hline & $150-174$ & 2 & 0,636 & 0,602 & 0,670 & 0,034 \\
\hline & $175-199$ & 1 & 0,574 & 0,574 & 0,574 & 0,000 \\
\hline & Genel Toplam & 46 & 0,716 & 0,289 & 1,000 & 0,173 \\
\hline \multirow{7}{*}{ 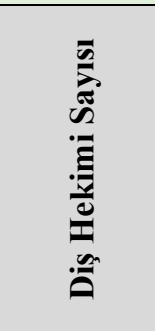 } & $25-49$ & 2 & 0,616 & 0,544 & 0,689 & 0,072 \\
\hline & $50-74$ & 21 & 0,812 & 0,622 & 1,000 & 0,118 \\
\hline & $75-99$ & 10 & 0,675 & 0,456 & 1,000 & 0,169 \\
\hline & $100-124$ & 9 & 0,644 & 0,344 & 0,847 & 0,182 \\
\hline & $125-149$ & 3 & 0,521 & 0,289 & 0,670 & 0,166 \\
\hline & $200-224$ & 1 & 0,574 & 0,574 & 0,574 & 0,000 \\
\hline & Genel Toplam & 46 & 0,716 & 0,289 & 1,000 & 0,173 \\
\hline \multirow{8}{*}{ 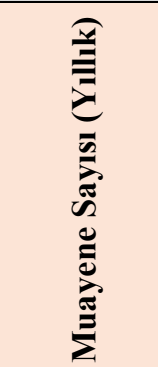 } & $100.000-199.999$ & 1 & 0,544 & 0,544 & 0,544 & 0,000 \\
\hline & $200.000-299.999$ & 13 & 0,625 & 0,289 & 0,899 & 0,186 \\
\hline & $300.000-399.999$ & 21 & 0,726 & 0,456 & 1,000 & 0,144 \\
\hline & $400.000-499.999$ & 5 & 0,895 & 0,693 & 1,000 & 0,132 \\
\hline & $500.000-599.999$ & 2 & 0,705 & 0,602 & 0,808 & 0,103 \\
\hline & $600.000-699.999$ & 2 & 0,833 & 0,820 & 0,847 & 0,014 \\
\hline & $700.000-799.999$ & 2 & 0,740 & 0,574 & 0,906 & 0,166 \\
\hline & Genel Toplam & 46 & 0,716 & 0,289 & 1,000 & 0,173 \\
\hline
\end{tabular}

Ünit sayılarına göre yapılan sınıflandırmada en yüksek ortalama VZA skoru 50-74 ünit aralığındaki 22 ADSM'ye ait bulunmuştur. Bu durumda, ünit sayısının az olmasının verimliliği artırdığı söylenebilir. Ayrıca en yüksek verimliliğe sahip merkezler, 50-74 arasında diş hekiminin görev yaptığı ADSM'ler olarak tespit edilmiştir. 125 ve üzerinde diş hekiminin görev yaptığı merkezlerin, en düşük ortalama verimlilik puanına sahip ADSM'ler olduğu anlaşılmıştır. Yıllık muayene sayıları incelendiğindeyse 400.000-499.999 arasında olan merkezler 0,895 ortalama ile en verimli merkezlerdir. En alt grupta ise, 100.000-199.999 arasında hasta muayene sayısı bulunan ADSM'ler en düşük ortalama CCR skorunu $(0,544)$ almışlardır.

Literatürdeki benzer çalışmalardan örneklere bakıldığında; Linna ve arkadaşları (2003) tarafından ağız ve diş sağlığı hizmeti sunan merkezlerde VZA ve Tobit modeli kullanılarak teknik ve maliyet etkinliğini (cost efficiency) açıklayan çeşitli faktörler araştırılmıştır. Maliyet etkinlik düzeyi, genellikle \%20 ile \%30 arasında bulunmuştur. Elde edilen sonuçlara göre, diş merkezlerindeki girdi 
tahsisinin daha fazla insan gücüne kaydırılmasıyla maliyet etkinliğinin iyileştirilemeyeceği görülmüştür. Beazoglou ve arkadaşları (2012); ABD’nin Colorado eyaletindeki 154 genel diş hekimliği kliniğinde anket ve VZA kullanarak, verimlilik ve etkinlik ölçme çalışması yapmıştır. Kliniklerin \%64'ünün yardımcı asistan ve sağlık personeli kullandığını, ortalama olarak \%31,4'ünün uygulamayı bu personele devrettiklerini tespit edilmiştir. Yardımcı sağlık personeli kullanan klinikler daha fazla hasta tedavi etmiş, brüt faturalama ve net gelirleri, yardımcı sağlık kullanmayanlara göre daha yüksek olduğu tespit edilmiştir.

Charalambous ve arkadaşları (2013); 2004-2007 yılları arasındaki Kıbrıs’ta kamu diş sağlığı merkezinin teknik verimliliğini ölçmek ve onu etkileyebilecek çeşitli faktörleri saptayabilmek amacıyla VZA ile iki ayrı model oluşturulmuştur. İlk modelde ortalama teknik etkinlik puanı \%68, ikinci modelde ise \%81 olarak saptanmıştır. Chen ve Bao (2014); Amerikan Diş Hekimliği Derneği (ADA)'nin 2005 anket verileriyle VZA yöntemini kullanarak dental uygulama verimliliğini değerlendirilmiştir. Toplam 117 KVB belirlenmiştir. Radyal çıktı odaklı VZA sonucunda, ortalama verimliliğin 0,907 olduğu bulunmuştur. Çıktı odaklı VZA'da 55, girdi odaklı VZA'da ise 103 KVB etkin çıkmıştır. İkinci aşamada regresyon analizi yapılmıştır. Buna göre genel teknik verimliliğin; rekabet yoğunluğu, diş hijyenistinin klinikteki yetkileri, kentsel alandaki hastaların yüzdesi ve sigortasız veya randevulara gelemeyen hastalar yüzdesi ile olumlu ilişkili olduğu tespit edilmiştir.

Gülcü ve arkadaşları (2004) tarafından Cumhuriyet Üniversitesi Diş Hekimliği Fakültesi’nin VZA yöntemiyle göreceli etkinlik analizi yapılmıştır. Birbiri ardına 3 yıl boyunca endodonti, pedodonti ve periodontoloji bölümleri verimli çıkmıştır. Ağız diş çene hastalıkları ve cerrahisi anabilim dalı her yıl verimsiz çıkan, her sene verimlilik skoru düşen tek bölüm olmuştur (Gülcü vd., 2004: 97 99). Özdemir (2011); Sağlık Bakanlığı'na bağlı 115 ADSM'nin etkinliği üzerine 2009 yılı verileri ile bir çalışma yapmıştır. ADSM'lerin CCR yöntemi analizleri sonucunda 70'inin $(\% 60,9)$ etkin çalışmadığı anlaşılmıştır. CCR yöntemiyle yapılan analizlerde ADSM'nin ortalama verimlilik skoru 83,55 $\pm 18,40$ olarak tespit edilmiştir. Özdemir (2011)'in çalışmasında ulaşılan verimsiz ADSM yüzdelerinin bu araştırmadan elde edilen sonuçlardan daha düşük olduğu ve ayrıca potansiyel iyileştirme oranlarının ise uyumlu olduğu söylenebilir. En verimli bölgenin Güneydoğu Anadolu bölgesi olarak bulunması da bu araştırma sonuçları ile örtüşmektedir.

Arslan (2017) tarafından yapılan araştırmada; 2015 yılı verileri kullanılarak 15 tane ADSH'nin etkinlikleri ölçülmüş, girdi yönelimli CCR sonuçlarına göre 4 ADSH'nin verimli olmadığı tespit edilmiştir. Etkin olmayan hastanelerin ortalama skorları \%93,39'tür. Kıraç ve Kıraç (2018) Türkiye'de bulunan Sağlık Bakanlığı'na bağlı toplam 21 tane ADSH'nin teknik verimliliklerini VZA yöntemi ile incelemişlerdir. CCR modeli için etkin ADSH sayısı 15 olarak hesaplanmıştır. Çalışmada dikkat çeken en değerli hususlardan birisi, etkin olmayan ADSH'ler için diş hekimi 
sayısı ve ünit sayısı girdilerinin azaltılması gerektiğidir. Sonuçlar, bu araştırmada ulaşılan potansiyel iyileştirme sonuçlarıyla uyumludur. Fakat Kıraç ve Kıraç tarafından bulunan verimsiz KVB ortalama skorlarının, bu çalışmaya göre daha yüksek olduğu gözlenmiştir.

Türkiye'deki 81 ilin ağız ve diş sağlı̆̆ında hizmet sunumunun değerlendirildiği bir başka araştırmada; illerin ortalama verimlilik skoru CCR modeline göre 0,844 olarak tespit edilmişstir. CCR modeline göre illerin \%17,3'ünün (14) verimli olduğu bulunmuştur (Yüksel ve Yiğit, 2019). Şahin ve İlgün (2018) yaptıkları araştırmada; Türkiye'nin 81 ilinde bulunan Sağlık Bakanlığı bünyesinde diş hekimliği hizmeti veren bütün hastane ve merkezler çalışma evrenini oluşturmuştur. CCR yönteminde 81 ilin 18'i verimli ve 63 il verimsiz bulunmuştur. Kullanılan girdilerin ortalama değerleriyle, söz konusu çalışma değerlerinin yakın seviyelerde olduğu görülmüştür.

Matranga ve arkadaşları (2014); sağlık sistemleri veri tabanından alınan bilgilerle İtalya'da 481 hastanenin 2007 yılı teknik etkinliğini ölçmüşlerdir. En yüksek etkinlik skorları kuzey-batı İtalya bölgesindeki hastanelerde $(75,7 \pm 15,1)$ alınmıştır. Çalışmanın ikinci kısmında etkinliğe etki eden faktörler, Tobit model ile değerlendirilmiştir. Sosyo-ekonomik durumun, hastaneler arasında verimlilik farklılıklarının oluşturulmasında önemli bir rol oynadığı sonucuna varılmıştır. Samsudin ve arkadaşları (2014); Malezya'da 25 kamu hastanesinin 2008-2010 yıllarına ait 3 yıllık süreçte etkinliğini ölçmüşlerdir. Etkinsizliğe etki eden faktörlerin Tobit modeliyle saptanmaya çalışıldığ araştırmada; günlük ortalama kabul edilen hasta sayısının, doktor başına ayakta tedavi sayısının ve hastane sınıflandırmasının hastane verimsizliği üzerinde önemli bir etkisi olduğu bulunmuştur. Yeşilyurt ve Salamov (2017) VZA ve Tobit ile Türkiye, Azerbaycan, Kazakistan, Türkmenistan, Kırgızistan ve Özbekistan devletlerinin sağlık sistemlerinin etkinliklerini ve etkinliğe etki eden faktörlerini karşılaştırmalı olarak incelemişlerdir. CCR ve BCC etkinlik analizleri sonucunda Kırgızistan ve Özbekistan`ın VZA puanları 1’den düşük bulunmuştur.

$\mathrm{Bu}$ çalışma ve literatürde yer alan diğer araştırma sonuçları birlikte ele alındığında; kullanılan değişkenlerin farklı olması, farklı yılları kapsamaları ya da veri elde etme yöntemlerindeki değişiklikler dikkat çekmektedir. Araştırmada, ADSM'ler için elde edilen etkinlik skorları mutlak sonuçlar olmayıp göreceli etkinlik sonuçlarıdır. ADSM yöneticileri bu durumu göz önünde bulundurarak, verimlilik düzeylerini en iyi yansıtacak girdi ve çıktı değişkenlerini seçerek etkinlik düzeylerini ölçmelidirler. ADSM'lerin belli dönemlerde performans düzeyleri izlenmeli, sonuçlar yönetim ve birim sorumluları ile paylaşılmalıdır. ADSM yöneticilerinde, kaynak kullanımı konusunda verimlilik bilinci geliştirilmeli ve merkezlerin iş yükü analizleri yapılarak insan kaynakları yönetim süreçleri iyileştirilmelidir. Sonraki çalışmalarda, ağız ve diş sağlığı hizmetlerinde çürük/kayıp/dolgulu diş sayısını gösteren DMFT indeksinin de çıktılar arasında alınması ve koruyucu ağız ve diş sağlığı uygulamalarının başarıları düzeyinin ölçülmesi önerilebilir. 
O. YÜKSEL

\section{KAYNAKÇA}

Ağırbaş, İ., Akbulut, Y. \& Önder, Ö. R. (2011). Atatürk dönemi sağlık politikası. Ankara Üniversitesi Türk Inkklap Tarihi Enstitüsü Atatürk Yolu Dergisi, 12(48), 733-748.

Alaiad, A., Najadat, H., Al-Mnayyis, N. \& Khalil, A. (2018). Associative classification of the jordanian hospitals efficiency based on DEA. 2018 IEEE Conference on Big Data and Analytics, ICBDA 2018, 23-26.

Al-Shammari, M., (1999), A multi-criteria data envelopment analysis model for measuring the productive efficiency of hospitals, International Journal of Operations \& Production Management, 19(9), 879-891.

Amemiya, T. (1984). Tobit models: A survey. Journal of Econometrics, 24(1-2), 3-61.

Arslan, B. (2017). A $\breve{g} ı z$ diş sağlı̆̆ hastanelerinin (ADSH) veri zarflama analizi (VZA) yöntemiyle teknik verimliliklerinin ölçülmesi. Yayımlanmamış Yüksek Lisans Tezi, Dokuz Eylül Üniversitesi, Sosyal Bilimler Enstitüsü, İşletme Anabilim Dalı Hastane ve Sağlık Kuruluşları Yönetimi Programı, İzmir.

Atasever, M., \& Örnek, M. (2018). Türkiye'de ă̆ız ve diş sağll̆̆g hizmetleri ve çalışan sorunlarl analizi. Ankara: Sasam Enstitüsü Yayınları.

Bayraktutan, Y., Arslan, İ. \& Bal, V. (2010). Sağlık bilgi sistemlerinin hastane performanslarına etkisinin veri zarflama ile incelemesi: Türkiye'deki göğüs hastalıkları hastanelerinde bir uygulama. Gaziantep Tip Dergisi, 16(3), 13-18.

Beazoglou, T. J., Chen, L., Lazar, V. F., Brown, L. J., Ray, S. C., Heffley, D. R., ... Bailit, H. L. (2012). Expanded function allied dental personnel and dental practice productivity and efficiency. Journal of Dental Education, 76(8), 1054-1060.

Bhat, R., Verma, B. B., \& Reuben, E. (1985). Envelopment analysis (DEA). Journal of Health Management, 3(2), 309-328.

Charalambous, C., Maniadakis, N., Polyzos, N., Fragoulakis, V. \& Theodorou, M. (2013). The efficiency of the public dental services (PDS) in Cyprus and selected determinants. BMC Health Services Research, 13(420), 1-9.

Charnes, A., Cooper, W., Lewin, A. Y., \& Seiford, L. M. (1996). Data envelopment analysis. USA: Kluwer Academic Publishers.

Charnes, A., Cooper, W. W., \& Rhodes, E. (1978). Measuring the efficiency of decision making units. XXI Simpósio Brasileiro de Recursos Hídricos, 2, 429-444.

Chen, L., \& Bao, W. (2014). A study of the production technology of the U.S. dental care 1ndustryA non-parametric approach. 11th International Conference on Service Systems and Service Management, ICSSSM 2014-Proceeding, 1-6.

Cingi, S. \& Tarım, Ş. A. (2000), Türk banka sisteminde performans ölçümü Dea-Malmquist TFP endeksi uygulaması, Türkiye Bankalar Birliği Araştırma Tebliğleri Serisi, 1, 1-34.

Deaton, A. \& Irish, M. (1984). Statistical models for zero expenditures in household budgets. Journal of Public Economics, 23(1-2), 59-80.

Farrell, M. J. (1957). The measurement of productivite efficiency. Journal of the Royal Statistical Society. Series A (General), 120(3), 253-290.

Greene, W. H. (2008). Economoetric analysis. New Jersey: Pearson Education Inc.

Gülcü, A., Coşkun, A., Yeşilyurt, C., Esener, T. \& Coşkun, S. (2004). Cumhuriyet Üniversitesi Diş Hekimliği Fakültesi'nin veri zarflama analizi yöntemiyle göreceli etkinlik analizi. C. $\ddot{U}$. İktisadi ve İdari Bilimler Dergisi, Cilt 5(2), 87-104. 
Gülsevin, G., \& Türkan, A. H. (2012). Afyonkarahisar hastanelerinin etkinliklerinin veri zarflama analizi ile değerlendirilmesi. Afyon Kocatepe Üniversitesi Fen Bilimleri Dergisi, 12, 1-8.

Kıraç, Y. \& Kıraç, S. (2018). Veri zarflama analizi yaklaşımını kullanarak ağız ve diş sağlı̆̆1 hastanelerinin (ADSH) verimlilik değerlendirmesi. Journal of International Management, Educational and Economics Perspectives, 6(2), 90-105.

Linna, M., Nordblad, A. \& Koivu, M. (2003). Technical and cost efficiency of oral health care provision in Finnish health centres. Social Science and Medicine, 56(2), 343-353.

Matranga, D., Bono, F., Casuccio, A., Firenze, A., Marsala, L., Giaimo, R., ... Vitale, F. (2014). Evaluating the effect of organization and context on technical efficiency: a second-stage DEA analysis of Italian hospitals. Epidemiology Biostatistics and Public Health, 11(1), 111.

Mohanta, A. (2017). Oral health in 21 st century-an emerging challenge. EC Dental Science, 8, 12 14.

Özata, M. (2004). Să̆lık bilişim sistemlerinin hastane etkinliğinin artırllmasında yeri ve önemi (Veri zarflama analizine dayalı bir uygulama). Yayımlanmamış Doktora Tezi, Selçuk Üniversitesi, Sosyal Bilimler Enstitüsü, Konya.

Özdemir, Y. (2011). Türkiye'deki Să̆llk Bakanlı̆̆ı'na bă̆lı ăglz ve dişs să̆lı̆ğ merkezlerinin veri zarflama analizi ile göreceli teknik verimliliklerinin ölçülmesi. Yayımlanmamış Yüksek Lisans Tezi, Hacettepe Üniversitesi, Sağlık Kurumları Yönetimi Programı, Ankara.

Ramanathan, R. (2005). Operations assessment of hospitals in The Sultanate of Oman. International Journal of Operations and Production Management, 25(1), 39-54.

Şahin, B. \& İlgün, G. (2018). Assessment of the efficiency of dental services in Turkey. Health Policy and Technology, 7(2), 173-181.

Şahin, İ. (2008). Sağlık bakanlığı genel hastaneleri ve sağlık bakanlığına devredilen SSK genel hastanelerinin teknik verimliliklerinin karşılaştırmalı analizi. Hacettepe Sağllk İdaresi Dergisi, 11(1), 1-48.

Salamov, F. (2017). Azerbaycan kamu hastanelerinde verimlilik ve etkinlik analizi. Yayımlanmamış Doktora Tezi, Sakarya Üniversitesi Sosyal Bilimler Enstitüsü, İktisat Anabilim Dalı, Sakarya.

Samsudin, S., Applanaidu, S. D., Jaafar, A. S., Ali, J., \& Majid, R. (2014). Performance of public hospitals in Malaysia and its determinants: An analysis using data envelopment and Tobit model. PAK Publishing Group, Handbook on the Emerging Trends in Scientific Research, 807-815.

Tarım, A. (2001). Veri zarflama analizi/matematiksel programlama tabanlı göreli etkinlik ölçüm yaklaşımı (araştırma). Sayıştay Yayın İşleri Müdürlüğü, 15, 5-40

TDB. (2019). Türk Dişhekimleri Birliği, Dişhekimlerinin çalışma şekilleri kurumlarda ve il/ilçelerde 2018 yılı dă̆ılımı. Ankara.

Temür, Y. (2010). İllerin gelişmişlik derecelerine göre hastanelerin etkinlik analizi. Uluda $\breve{g}$ Üniversitesi İktisadi ve İdari Bilimler Fakültesi Dergisi, 29(2), 1-22.

Tütek, H. H., Gümüşoğlu, Ş., \& Özdemir, A. (2012). Sayısal yöntemler: Yönetsel yaklaşımlar. İstanbul: Beta Basım Yayım Dağıtım.

Uğurluoğlu, Ö. \& Çelik, Y. (2005). Sağlık sistemleri performans ölçümü, önemi ve dünya sağlık örgütü yaklaşımı. Hacettepe Sağllk İdaresi Dergisi, 8(1), 3-29.

Wang, B. B., Ozcan, Y. A., Wan, T. T. H. \& Harrison, J. (1999). Trends in hospital efficiency among metropolitan markets. Journal of Medical Systems, 23(2), 83-97. 
WHO. (1948). Constitution of The World Health Organization. New York.

Yeşilyurt, C. \& Alan, M. A. (2003). Fen liselerinin 2002 yılı göreceli etkinliğinin veri zarflama analizi (VZA) yöntemi ile ölçülmesi. C. Ü. İktisadi ve İdari Bilimler Dergisi, 4(2), 91-104.

Yeşilyurt, Ö. \& Salamov F. (2017). Türk devletleri sağlık sistemlerinde etkinliğin ve etkinliğe etki eden faktörlerin süper etkinlik ve tobit modelleriyle değerlendirilmesi. Balkan ve Yakın Doğu Sosyal Bilimler Dergisi, III. IBANESS Congress Series-Edirne/Turkey.

Yiğit, A. (2020). Türkiye'de hastane verimliliğinin meta analiz yöntemiyle tespit edilmesine yönelik bir araştırma. SDÜ Sağlık Bilimleri Enstitüsü Dergisi, 11(1), 24-32.

Yüksel, O. \& Yiğit, V. (2019). Ağız ve diş sağlığı hizmetlerinin iller bazında teknik verimlilik analizi. Journal of Academic Value Studies (JAVStudies), 5(3), 312-323. 